\title{
EL SISTEMA TRIBUTARIO PERUANO Y SU PENDIENTE REESTRUCTURACIÓN
}

\section{THE PERUVIAN TAX SYSTEM AND ITS PENDING RESTRUCTURING}

\section{EdUARdo A. Montes FARRo*}

Docente Asociado de la Facultad de Ciencias Contables, UNMSM

[Recepción: Marzo de 2009 / Conformidad: Mayo de 2009]

\section{RESUMEN}

El sistema tributario adolece de bastantes defectos de fondo y de forma. Es necesario un replanteamiento integral que permita un amplio universo de contribuyentes, de fácil entendimiento, cumplimiento y control. Debe tener como fundamento la claridad, precisión, equidad y justicia.

Palabras clave: Unidad Impositiva Tributaria (UIT), afectos, base imponible.

\begin{abstract}
The tax system suffers from several defects in substance and form. We need a comprehensive rethinking, enabling a broad universe of taxpayers, easy understanding, compliance and control. Must be based on clarity, accuracy, fairness and justice.
\end{abstract}

Key words: Tax Revenue Unit (ITU) has an impact, taxable.

\footnotetext{
Contador Público Colegiado.
} 


\section{INTRODUCCIÓN}

No es ninguna novedad decir que el sistema tributario actual necesita ser reestructurado, tanto por la visión que lo inspiró y por la serie de incongruencias que posee.

El sistema vigente privilegia las posibilidades recaudatorias a corto plazo y distorsiona principios y criterios de derecho, economía, administración y de contabilidad.

Se observa, entre otras cosas, exoneraciones excesivas, procedimientos muy cambiantes e injustos. Es decir se trata de un sistema no eficiente; $y$ muchas veces no equitativo.

No terminamos de acostumbrarnos a la práctica de las modificaciones constantes y los procedimientos complicados, para el cumplimiento de las obligaciones tributarias.

La afectación y procedimientos para el cálculo del impuesto, como de los pagos a cuenta, se amparan en la Ley y su reglamentación. Veremos un ejemplo para ilustrar tan particular situación.

\section{EL IMPUESTO A LA RENTA DE QUINTA CATEGORÍA}

Este impuesto está dentro del marco legal del Texto Único Ordenado de la Ley del Impuesto a la Renta, D.S. No. 179 y sus modificatorias (por supuesto), Reglamento de la Ley del Impuesto a la Renta, D.S. N. 122-94 y Normas Reglamentarias y Ley 28655 vigente desde 1 enero del 2006.

Los criterios para la aplicación de este impuesto son:

- Afectos: Los trabajadores dependientes señalados en la ley, por las rentas que perciban en el ejercicio correspondiente.

- Agentes de retención: Quienes paguen rentas consideradas de quinta categoría, es el obligado a retener, declarar y entregar el impuesto al Fisco.

- Base Imponible: Toda retribución por servicios personales con relación de dependencia.

- Deducciones: Anualmente, el monto correspondiente a siete Unidades Impositivas Tributarias (UIT).

Procedimiento determinado para el cálculo:

a) Se establece la Renta Bruta Anual Proyectada: Remuneración mensual por el número de meses del año, más gratificaciones ordinarias del ejercicio y otras remuneraciones del mes.

b) Si los ingresos fueran mayores el monto de siete UIT estará afecto, y el exceso se constituye en la Renta Anual Neta Proyectada.

c) Se aplicará la tasa de $15 \%, 21 \%$ y $30 \%$ de acuerdo a rangos de hasta 27 UIT, hasta 54 UIT y mayor de 54 UIT, respectivamente.

En el acápite f) del Reglamento dice: El impuesto así determinado en cada mes, se fraccionará de la siguiente manera:

1. En los meses de enero a marzo, el impuesto anual se dividirá entre doce.

2. En el mes de abril, al impuesto anual se le deducirá las retenciones efectuadas de enero a marzo del mismo ejercicio. El resultado de esta operación se dividirá entre 9 .

3. En los meses de mayo a julio, al impuesto anual se le deducirá las retenciones efectuadas en los meses de enero a abril del mismo ejercicio. El resultado de esta operación se dividirá entre 8 .

4. En el mes de agosto, al impuesto anual se le deducirán las retenciones efectuadas en los meses de enero a julio del mismo ejercicio. El resultado de esta operación se dividirá entre 5 . 


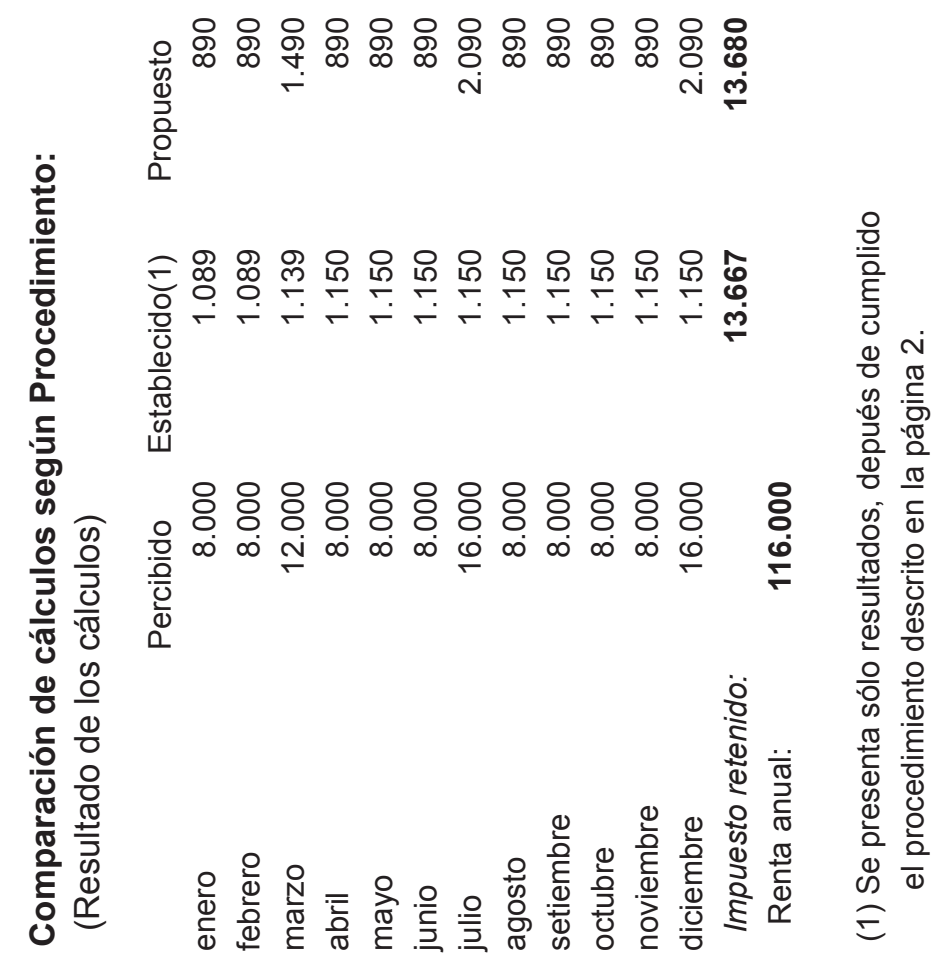

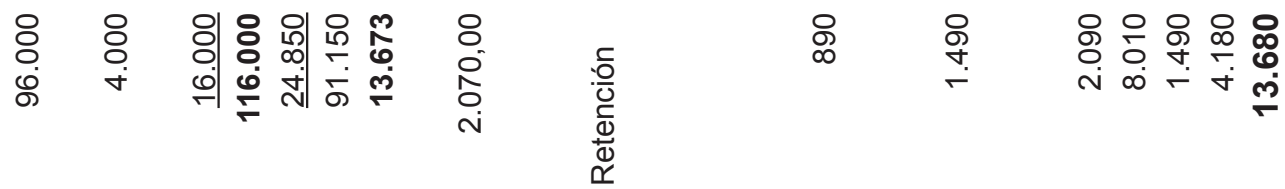

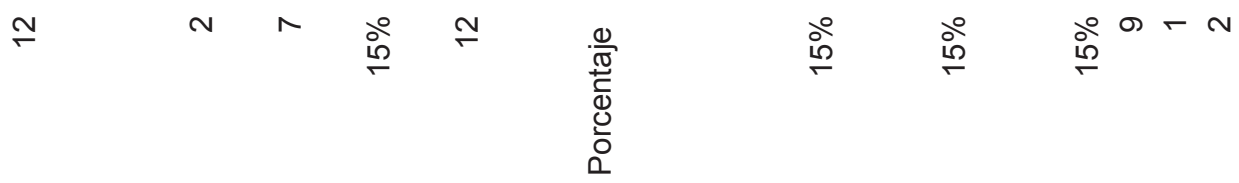

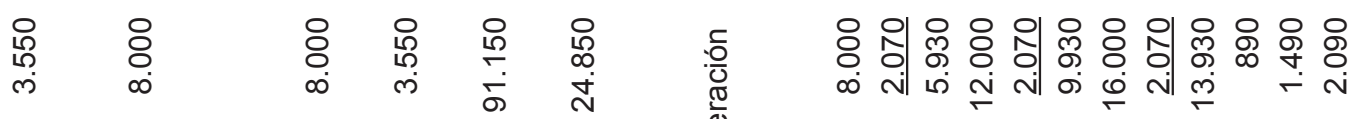

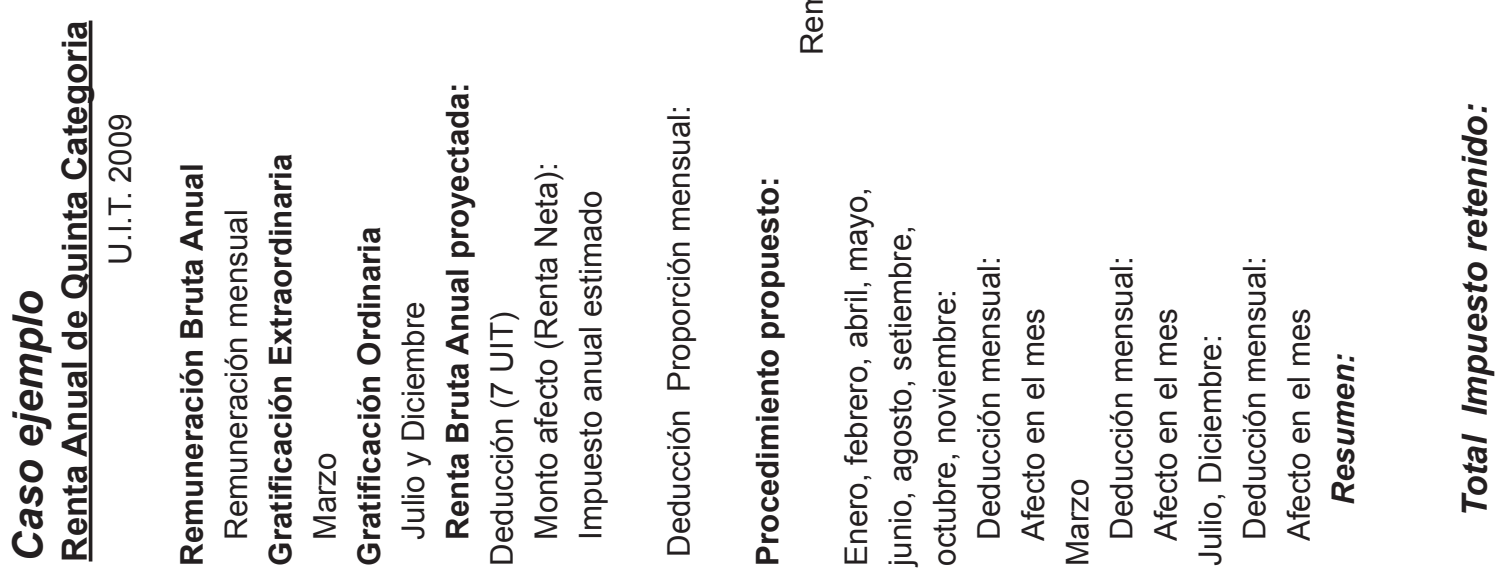


5. En los meses de septiembre a noviembre, al impuesto anual se le deducirán las retenciones efectuadas en los meses de enero a agosto del mismo ejercicio. El resultado de esta operación se dividirá entre cuatro.

6. En el mes de diciembre, con motivo de la regularización anual, al impuesto anual se le deducirá las retenciones efectuadas en los meses de enero a noviembre del mismo ejercicio.

El monto obtenido por aplicación del procedimiento antes indicado, será el impuesto a retener en cada mes.

Utilizando este tipo de fraccionamiento dará como resultado un aporte mensual uniforme, que puede ser beneficioso para los ingresos estatales, pero que perjudica al trabajador que no puede disponer de sus ingresos, pagando a cuenta sobre lo no percibido.

Estimamos necesario tener en cuenta dos situaciones separadas:

1) Calcular el monto estimado que ganará el empleado en el periodo; para poder determinar si está afecto o no al impuesto.

2) Si está afecto, se debe calcular la retención respectiva.

No debe retenerse un impuesto sin haberse devengado. Sería más razonable que se calcule, el impuesto a retener, sobre lo pagado.

Se puede observar que en los dos procedimientos, la retención anual es semejante.

Sin embargo, en nuestra propuesta el cálculo es más sencillo, comparado con el procedimiento actual, que es bastante laborioso.
En cuanto a la legitimidad, lo más apropiado es que se retenga sobre lo percibido.

\section{CONCLUSIONES}

Por lo expuesto, si fuera el único caso, debería utilizarse un procedimiento diferente al vigente antes descrito. Pero el problema es más amplio y estructural; por lo que se recomienda el establecimiento de un nuevo sistema tributario, basados en principios de equidad y eficiencia.

Es nuestro propósito contribuir a entender que los tributos, tanto en sus fundamentos como en sus procedimientos de cumplimiento, deben estar inspirados en la justicia y desarrollo nacional.

\section{REFERENCIAS BIBLIOGRÁFICAS}

1. Texto Único Ordenado de la Ley del Impuesto a la Renta, D.S. No. 179 y sus modificatorias

2. Reglamento de la Ley del Impuesto a la Renta, D.S. No. 122-94

3. Ley 28655 vigente desde 1 enero del 2006

4. Informativo Caballero Bustamante - Revista de Asesoría Especializada

5. Informativo Actualidad Económica - Revista de Asesoría Especializada

6. Página web de la Sunat. 